\title{
Optimization of Nonlinear Lamb Wave Detection System Parameters in CFRP Laminates
}

\author{
Zhenhua Yin, Ying Tie, Yuechen Duan and Cheng Li * D \\ School of Mechanical and Power Engineering, Zhengzhou University, Science Road 100, \\ Zhengzhou 450001, China; yinzhenhua@gs.zzu.edu.cn (Z.Y.); tieying@zzu.edu.cn (Y.T.); \\ duanyc1984@zzu.edu.cn (Y.D.) \\ * Correspondence: chengli@zzu.edu.cn
}

Citation: Yin, Z.; Tie, Y.; Duan, Y.; Li, C. Optimization of Nonlinear Lamb Wave Detection System Parameters in CFRP Laminates. Materials 2021, 14, 3186. https://doi.org/10.3390/ ma14123186

Academic Editor: Patricia Krawczak

Received: 14 May 2021

Accepted: 7 June 2021

Published: 9 June 2021

Publisher's Note: MDPI stays neutral with regard to jurisdictional claims in published maps and institutional affiliations.

Copyright: (c) 2021 by the authors. Licensee MDPI, Basel, Switzerland. This article is an open access article distributed under the terms and conditions of the Creative Commons Attribution (CC BY) license (https:// creativecommons.org/licenses/by/ $4.0 /)$.

\begin{abstract}
Carbon fiber reinforced polymer (CFRP) laminates, as unique multifunctional materials, are widely applied in various aircraft, such as airliners, fighter planes, and space shuttles. To ensure aircraft safety during the production and application of CFRP laminates, it is necessary to improve the accuracy of nonlinear Lamb wave nondestructive testing to assess the damage in CFRP laminates caused by impact, high temperature, friction, corrosion, etc. In this study, the accuracy of nonlinear ultrasonic nondestructive testing was found to highly depend on the cycle number, output level and gain of the nonlinear ultrasonic detection system. Based on a single-factor experiment that considered the cycle number, output level, and gain of the amplifier as independent variables, a regression analysis was carried out on the fundamental wave amplitude value $\left(\mathrm{A}_{1}\right)$ and second harmonic amplitude value $\left(A_{2}\right)$. Two response surface surrogate models were established to improve the accuracy of nonlinear Lamb wave nondestructive testing and to optimize the detection system parameters. The response surface models were verified via an analysis of variance (ANOVA), significance tests and an error statistical analysis. The results revealed the significant influence of these three factors on $A_{1}$ and $A_{2}$. Optimization of the response surface was achieved at eight cycles, an output level of 42 and a gain of $32 \mathrm{~dB}$. Moreover, the nonlinear ultrasonic detection system achieved good operational stability, high accuracy and reliability under the above optimal parameter conditions. This approach provides scientific guidance for the accurate assessment of CFRP laminate damage.
\end{abstract}

Keywords: CFRP laminates; response surface methodology; nonlinear Lamb wave; fundamental wave; second harmonic

\section{Introduction}

Carbon fiber reinforced polymer (CFRP) laminates are extensively applied in the electronics, military, and aerospace fields due to their excellent mechanical properties [1-4]. One of CFRP laminates' critically important characteristics is an unusually high anisotropy $[5,6]$. Although CFRP laminates have many advantages, their production process is complex, and damage, such as fracturing, delamination and debonding, inevitably occurs during the application process [7-9]. Especially for aircraft composite structures during service, the environment faced is extremely complicated and quite harsh, and it is easily affected by various conditions, such as hail strikes, bird strikes, lightning strikes, and tool drops [10,11]. Damage poses a great potential danger to the safety of the material structure. Additionally, the frequency dispersion of CFRP laminates is significant, which prevents their applications in conventional nondestructive detection methods. Therefore, the development of new detection equipment and methods is necessary to identify manufacturing defects, control the quality of the final product, and ensure the safety of personnel.

In recent years, ultrasonic nondestructive detection has been widely adopted in the assessment of the safety of material structures. According to the different mechanisms of damage interaction, ultrasonic detection technology is usually classified into linear and 
nonlinear techniques $[12,13]$. Compared to linear ultrasonic detection, nonlinear Lamb waves have attracted much attention in the material characterization and detection of barely visible damage due to their higher sensitivity [14,15]. The method of detection and evaluation that involves nonlinear ultrasonic nondestruction mainly capitalizes on signal characteristics in the frequency domain to discriminate defects, which overcomes the defects of traditional ultrasonic detection techniques [16-19]. Moreover, nonlinear Lamb waves are almost nondispersive in anisotropic media so that different harmonics effectively interact in the process of wave propagation.

Nonlinear Lamb waves detect not only visible damage, such as external cracks, but also invisible damage, such as internal delamination and bonding defects, in CFRP laminates $[20,21]$. Therefore, nonlinear Lamb wave-based higher-harmonic detection methods have increasingly been adopted by researchers to evaluate the structural safety of composite materials [22,23]. Tie et al. [24] investigated the impact damage to CFRP laminates under different impact energies via finite element and experimental methods based on the higher harmonics of nonlinear Lamb waves. This work proposed an integrated numerical model to study the interaction relationship between nonlinear Lamb wave propagation and low-velocity impact damage. Yang et al. [25] experimentally and theoretically analyzed the second harmonic signal generated by the nonlinear interaction between nonlinear Lamb wave propagation and fatigue cracks in materials and demonstrated that the threedimensional (3D) finite element method could properly predict the double-frequency signal due to the material contact nonlinearity that occurs at fatigue cracks. Carboni et al. [26] investigated a structural health monitoring approach based on nonlinear Lamb wave detection, which matched the out-of-phase driving of low-frequency piezoceramic transducers. Via the design of an experimental statistical method that considered the pulse echo and pitch capture configurations of piezoceramic transducer (PZT) sensors, several factors and their interactions effectively affected the detection of delamination damage. Although some of the existing studies have mainly focused on the application of nonlinear ultrasonic nondestructive testing for damage (e.g., cracks, delamination, and impact) assessment in CFRP laminates. However, there are still few studies on the optimization of nonlinear ultrasonic detection-related parameters in CFRP laminates.

To improve the precision and application of nonlinear ultrasonic detection, the extraction of a suitable fundamental wave amplitude value $\left(\mathrm{A}_{1}\right)$ and second harmonic amplitude value $\left(A_{2}\right)$ is very important and difficult, because both $A_{1}$ and $A_{2}$ are affected by several factors and should be considered simultaneously, including noise interference with the instrument, filter use, amplitude of the driving voltage, and coupling with media. To accurately extract nonlinear signals to determine the state of material characterization, harmonic interference induced by the measuring instrument or random factors should be reduced to optimally simplify the frequency components of the transmitted signal for proper setting and selection. Therefore, it is necessary to study $A_{1}$ and $A_{2}$ under different conditions to better understand the effect of various factors (e.g., cycle number, output level, and gain) on the nonlinear ultrasonic detection system stability. The response surface method (RSM) is an effective statistical method [27] that relies on the reasonable design of experiment (DOE) method $[28,29]$ to obtain certain data through tests, applies multiple quadratic regression equations to fit a functional relationship between the factors and response values, and determines the optimal process parameters through the analysis of regression equations to solve multivariable problems. While reducing the number of experiments, damage to the materials can be predicted, which greatly reduces costs. The RSM mainly includes the Box-Behnken design, central composite design (CCD), full factorial design, and PlackettBurman design. Among these approaches, CCD comprises three parts, namely, a $2^{n}$ ( $n$ is the factor) full factorial design, an axis point design, and zero level of the center point repetition test. The second-order polynomial of each influencing factor is considered to predict its effect on the evaluation index. The CCD method expands the design space and provides sample data regarding the response surface approximation model, which yields the advantages of a simple design, fewer trials, and good predictability. CCD has been 
widely adopted by researchers because it facilitates time, money, and manpower reduction. In addition, the RSM involving statistical optimization overcomes the shortcomings of traditional methods and examines the relationship between the independent variables via the fitting of quadratic polynomial regression equations. Therefore, this method has been widely applied in the experimental design and optimization of wastewater treatment, organic synthesis, food science, and other fields [30,31]. The detection-related parameters need to establish RSM model to be optimized and obtain their optimal detection conditions because the inaccuracy of nonlinear Lamb wave detection results for damage of CFRP laminates in aircraft structures. However, to the best of our knowledge, few studies have been performed to explore $A_{1}$ and $A_{2}$ by optimizing the conditions of nonlinear Lamb wave detection system parameters using the DOE method.

In this study, based on different parameter settings in the RAM-5000 SNAP nonlinear ultrasonic detection system, according to the CCD design principle of the RSM, the experimental conditions of the nonlinear ultrasonic nondestructive testing amplitudes $\mathrm{A}_{1}$ and $A_{2}$ were optimized. Mathematical regression models of $A_{1}$ and $A_{2}$ were established by the RSM with the cycle number, output level and gain as the independent variables, and the average values of $A_{1}$ and $A_{2}$ retrieved from three parallel tests were adopted as the response value. The optimal experimental conditions were explored by RSM, and a theoretical basis for further studies on nonlinear ultrasonic detection was provided. This simple and reliable evaluation method of material damage may greatly improve the accuracy of online, dynamic, and real-time aircraft structural health monitoring (SHM) systems of aircraft composites during operation, and achieve a qualitative leap in safety monitoring and the performance of engineering structures. The rest of this paper is arranged as follows. Section 2 introduces the experimental study, including the RAM-5000 SNAP nonlinear ultrasonic detection system setup, RSM model experimental design, calculation of the ultrasonic nonlinear parameter and relative error. Section 3 describes the nonlinear ultrasonic detection method, the effect of single-factor experiments on $A_{1}$ and $A_{2}$, and the response surface model analysis. Section 4 presents the results and discussion and proposes the optimal experimental design parameters. Finally, this paper ends with a conclusion.

\section{Experimental Study}

\subsection{Experimental Setup}

A frequency-sweep analysis of the transducer is conducted to obtain its frequency response and select the appropriate excitation frequency. Frequency-sweep tests are carried out with superheterodyne technology and the phase-sensitive detector of a RAM-5000 SNAP system (RITEC Inc., Warwick, RI, USA), with the nonlinear Lamb wave signal chosen as the integral window. In this experiment, two ultrasonic transducers, one with a central frequency of 2.25 MHz (Olympus NDT Panametrics, A542S, Olympus, WA, USA) and the other with a central frequency of $5 \mathrm{MHz}$ (Olympus NDT Panametrics, V543, Olympus, WA, USA), are applied as excitation and receiving transducers, respectively. Figure 1 shows the frequency response range of these two transducers. The excitation transducer is a narrowband longitudinal ultrasonic transducer, and the receiver is a broadband longitudinal ultrasonic transducer.

The damaged material tested in the experiment was a T9001 CFRP laminate (Weihai Guangwei Composites Co., Ltd., Weihai, China) cut with a high-pressure water jet cutter (Anhui Aoyu CNC Technology Co., Ltd., Chuzhou, China). The CFRP laminate consists of 24 layers with a total thickness of $3.6 \mathrm{~mm}$ and linear dimensions of $360 \times 250 \mathrm{~mm}^{2}$. The layer stacking sequence is $[45 / 0 /-45 / 90]_{3 s}$, and the single-layer thickness is $0.15 \mathrm{~mm}$.

A RAM-5000 SNAP nonlinear ultrasonic detection system is employed to generate high-power tone burst signals [32], and the frequency, cycle number, output level and gain of the signals can be conveniently and flexibly set through a computer-controlled panel, as shown in Figure 2a. A block diagram of the setup is shown in Figure 2b. Its key component, the RAM-5000 SNAP detection system, emits sequences of tone burst cycles attenuated by $4 \mathrm{~dB}$. After the $2.25 \mathrm{MHz}$ low-frequency filter group removes any 
high-frequency interference generated by the device, the transducer with a center frequency of $2.25 \mathrm{MHz}$ generates ultrasonic Lamb waves that enter the samples. The broadband transducer $(5 \mathrm{MHz})$ is employed to receive the propagated signal via the fundamental wave channel $\left(\mathrm{CH}_{1}\right)$ and second harmonic channel $\left(\mathrm{CH}_{2}\right)$. After $4.5 \mathrm{MHz}$ high-pass filtering and $20 \mathrm{~dB}$ preamplification, the signal is received at $\mathrm{CH}_{2}$, after which it enters the RAM-5000 SNAP system for signal extraction and processing. A photograph of the experimental test system is shown in Figure 2c.

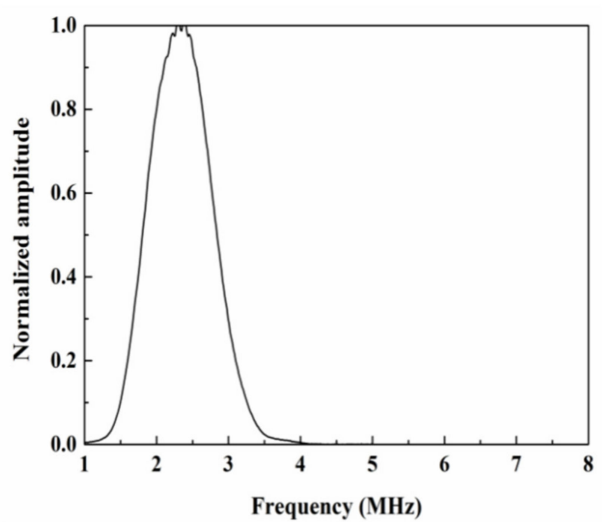

(a)

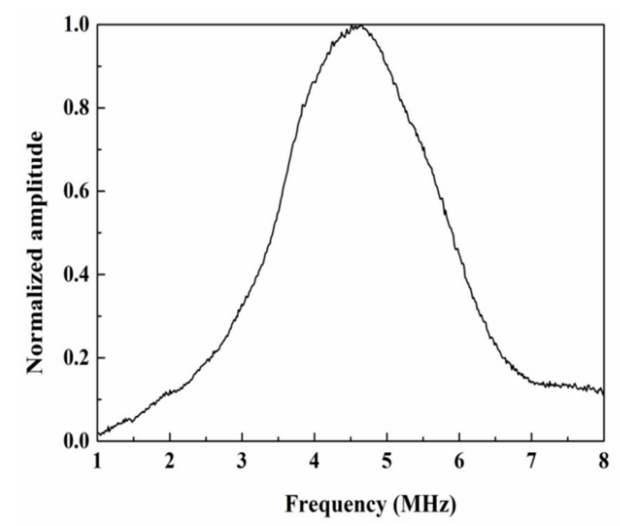

(b)

Figure 1. Frequency response range of the (a) excitation and (b) receiving transducers.

Nonlinear Lamb waves are excited and received in the CFRP laminates through two longitudinal ultrasonic transducers mounted on Plexiglas wedges at an angle of $45^{\circ}$. The optimal distance between the Plexiglas wedges is $60 \mathrm{~mm}$. Mount 7501 high-vacuum silicone grease is applied as the coupling agent, and the excitation and receiving transducers are positioned along the same straight line. A special fixture is employed to ensure full coupling between the sensors and samples during detection under constant pressure.

In this study, three main parameter settings that cycle numbers ranging from 5 to 14 , the output level ranging from 30 to 55 and the gain ranging from 28 to 50 are considered. The nonlinear Lamb wave detection system is used to measure the sample response under the same conditions three times; then, the average value is taken as $A_{1}$ and $A_{2}$. To overcome the effect of random noise generation, the relative error of the repeated measurement is set below $1.5 \%$.

\subsection{Response Surface Model Experimental Design}

The RSM model relies on CCD to optimize the most effective variables under the parameter setting conditions of the RAM-5000 SNAP nonlinear ultrasonic detection system and to study their mutual relationships. Based on the one-factor experimental results, the number of cycles $\left(x_{1}\right)$, output level $\left(x_{2}\right)$, and gain $\left(x_{3}\right)$ are chosen as the three independent variables. $A_{1}$ and $A_{2}$ averaged over three parallel tests are selected as the response values for the regression analysis with the RSM model considering 3 factors and 5 levels. Each parameter of this model was set according to various five-level codes $(-2,-1,0,1$, and 2), and the detailed range and level results of the experimental design factors are listed in Table 1.

Table 1. Experimental design factors range and levels.

\begin{tabular}{ccccccc}
\hline \multirow{2}{*}{ Factors } & Variable & \multicolumn{5}{c}{ Range and Coded Levels } \\
\cline { 3 - 7 } & & $\mathbf{- 2}$ & $\mathbf{- 1}$ & $\mathbf{0}$ & $\mathbf{1}$ & $\mathbf{2}$ \\
\hline Cycle number & $x_{1}$ & 5 & 7 & 9 & 11 & 13 \\
Output level & $x_{2}$ & 35 & 40 & 45 & 50 & 55 \\
Gain (dB) & $x_{3}$ & 28 & 34 & 40 & 46 & 52 \\
\hline
\end{tabular}




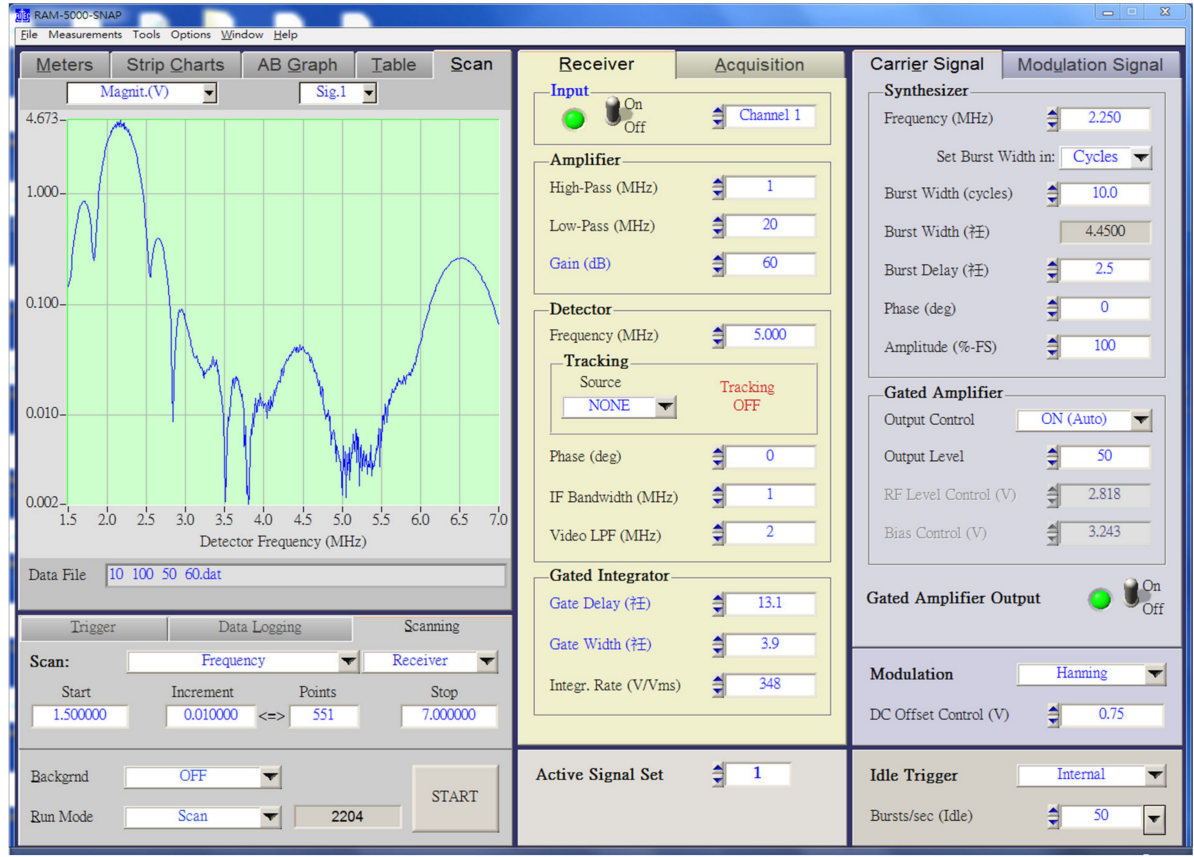

(a)

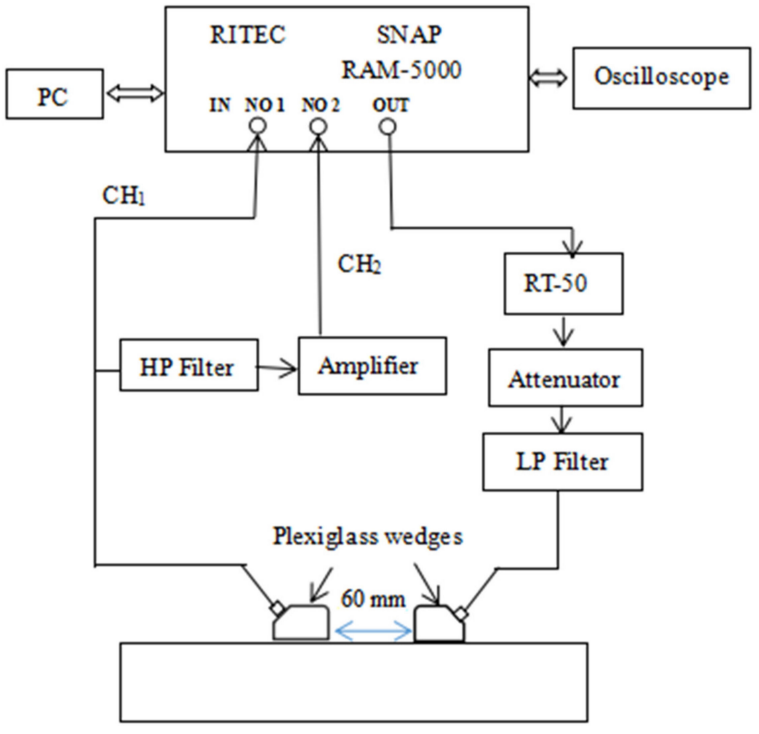

(b)

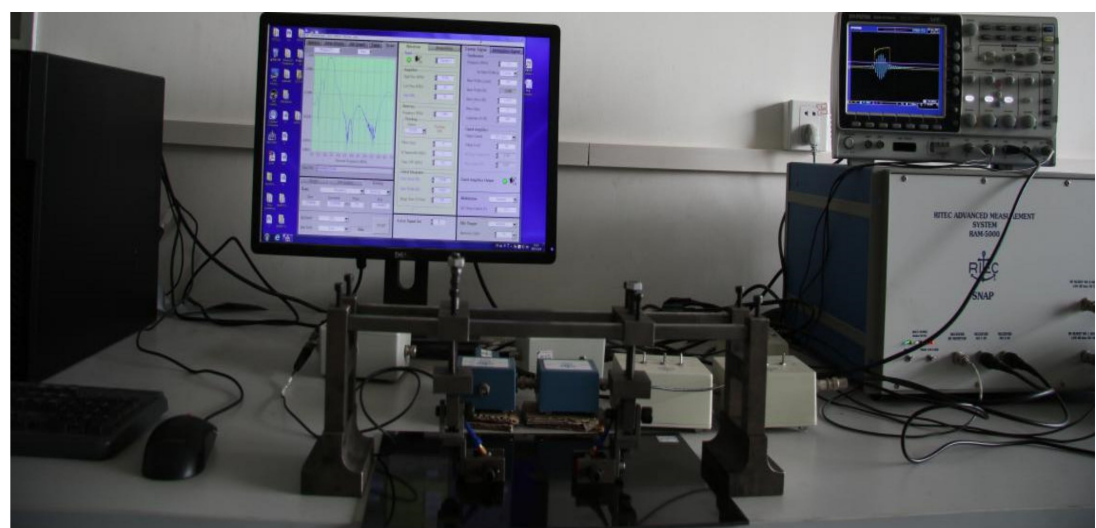

(c)

Figure 2. Nonlinear ultrasonic detection system: (a) Computer-controlled RAM-5000 SNAP ultrasonic detection system parameter settings, (b) block diagram of the experimental system setup, and (c) photograph of the experimental system. 
In the regression analysis equation, the actual values are converted into coded values as follows:

$$
X_{i}=\left(x_{i}-x_{0}\right) / \Delta x
$$

where $X_{i}$ denotes the coded value of the independent variable, $x_{i}$ represents the actual value of the independent variable at the $i$ th level, $x_{0}$ indicates the actual value of the independent variable at the center point, and $\Delta x$ is the step change value.

The experimental data of CCD are fitted to a second-order polynomial regression Equation (2) via the RSM.

$$
\begin{aligned}
y=a+a_{1} x_{1} & +a_{2} x_{2}+a_{3} x_{3}+a_{12} x_{1} x_{2}+a_{13} x_{1} x_{3}+a_{23} x_{2} x_{3}+a_{11} x_{1}^{2}+a_{22} x_{2}^{2}+a_{33} x_{3}^{2} \\
& =\left[\begin{array}{llll}
1 & x_{1} & x_{2} & x_{3}
\end{array}\right]\left[\begin{array}{cccc}
a & \frac{a_{1}}{2} & \frac{a_{2}}{2} & \frac{a_{3}}{2} \\
\frac{a_{1}}{2} & a_{11} & \frac{a_{12}}{2} & \frac{a_{13}}{2} \\
\frac{a_{2}}{2} & \frac{a_{12}}{2} & a_{22} & \frac{a_{23}}{2} \\
\frac{a_{3}}{2} & \frac{a_{13}}{2} & \frac{a_{23}}{2} & a_{33}
\end{array}\right]\left[\begin{array}{c}
1 \\
x_{1} \\
x_{2} \\
x_{3}
\end{array}\right]
\end{aligned}
$$

where $y$ is the predicted response value; $x_{1}, x_{2}$, and $x_{3}$ are the actual values of the independent variables; $a$ is a constant coefficient; $a_{1}, a_{2}$, and $a_{3}$ are the linear-effect coefficients; $a_{11}, a_{22}$, and $a_{33}$ are the squared effect coefficients; $a_{12}, a_{13}$, and $a_{23}$ are the interaction effect coefficients. The results are analyzed graphically and statistically with Design-Expert software to determine the interaction relationship among the above three factors to finally obtain the RSM model.

\subsection{Calculation of the Ultrasonic Nonlinear Parameter and Relative Error}

Based on the isotropic assumption of nonlinear acoustic theory, in the early stage of material damage, the distribution in different directions has less effect on the mechanical properties of the material. Therefore, it is assumed that material damage does not lead to anisotropy of the material. For this reason, the anisotropy analysis of material is summarized in isotropic to study.

In the case of small strain, if attenuation during propagation is neglected. Consider the one-dimensional plane wave in the $x y$ plane. Assuming that the wave propagates only along the $x$-axis, the particle displacement $u$ is related only to the position $x$ and time $t$. The wave equation is obtained, as follows:

$$
\rho \frac{\partial^{2} u}{\partial t^{2}}=\frac{\partial \sigma}{\partial x}
$$

where $\rho$ is the density and $\sigma$ is the stress.

Ultrasonic Lamb waves are distorted due to their nonlinear interaction with the composite material during propagation, which may generate high-order harmonic components. Based on the physical mechanism, the wave beam response phenomenon is caused by the nonlinearity of the material elastic behavior. According to the nonlinear Hooke law [33], the interaction between $\sigma$ and strain $\varepsilon$ is as follows:

$$
\sigma=E \varepsilon(1+\beta \varepsilon+\cdots)
$$

where $E$ is Young's modulus of the material; and $\beta$ is the absolute nonlinear elastic constant of the second-order [34], which is due to the wave interaction with the imperfect interfaces causing a local change in the stiffness at that region.

According to perturbation approximation theory [35], the approximate solution of the one-dimensional nonlinear wave Equation (3) in an isotropic solid is expressed in Equation (5).

$$
\beta=\frac{8}{k^{2} x} \frac{\mathrm{A}_{2}}{\mathrm{~A}_{1}^{2}}
$$


where $A_{1}$ is the amplitude at $\omega, A_{2}$ is the amplitude at $2 \omega, k=\omega / v(k$ is the wavenumber, which is proportional to the square root of Young's modulus, $v$ is the ultrasonic phase velocity), and $x$ is the Lamb wave propagation distance.

When the detection conditions remain the same, $k$ and $x$ should be kept constant. Therefore, Equation (5) can be simplified, then the relative acoustic nonlinear parameter $\beta^{\prime}$ is introduced [36,37] and represents a generalized parameter associated with the nonlinear properties of Lamb waves.

$$
\beta^{\prime} \propto \frac{A_{2}}{A_{1}^{2}}
$$

$\beta^{\prime}$ is a quantitative indicator that can be used to characterize the microdamage degree in CFRP laminates in the following discussion. When $\beta^{\prime}$ is larger, the internal damage in the CFRP laminate is more serious, and vice versa.

The absolute error is considered to estimate the error range between the actual and predicted response values of $A_{1}$ and $A_{2}$, and the relative error is considered to determine the reliability of the response surface model according to Equations (7) and (8), respectively.

$$
\begin{gathered}
\Delta=L-L_{0}^{\prime} \\
\delta=\frac{\Delta}{L_{0}^{\prime}} \times 100 \%
\end{gathered}
$$

where $L$ denotes the actual value of $A_{1}$ and $A_{2}, L_{0}^{\prime}$ represents the predicted values of $A_{1}$ and $\mathrm{A}_{2}, \Delta$ is the absolute error, and $\delta$ is the relative error.

\section{Experimental Work}

\subsection{Nonlinear Lamb Wave Detection}

According to the setup of the nonlinear ultrasonic detection system, as shown in Figure $2 b$, the experiment adopts the sensor arrangement method [38], where one transducer excites and the other transducer receives components to measure $A_{1}$ and $A_{2}$, respectively. To minimize the generation of harmonics, the transmitted signal should not overlap the received signal during propagation in the sample. Therefore, we apply sine pulse excitation in the experiment and record the received signal with an oscilloscope, conduct additional Hanning window debugging, and observe the oscilloscope waveform to ensure that the measured samples generate a single-mode Lamb wave. The fast Fourier transform (FFT) is utilized to convert the signals from a time-domain representation to the frequency domain to be stored on the computer.

At an excitation frequency of $2.25 \mathrm{MHz}$ and a cycle number of 9, the time-domain signals of Lamb waves are recorded with the oscilloscope, as shown in Figure 3. The frequency-domain signal during the various cycles is shown in Figure 4 . Then, $\mathrm{A}_{1}$ and $\mathrm{A}_{2}$ are extracted, and with an increasing number of cycles, the amplitude continues to increase, and the signal is significantly enhanced.

\subsection{Single-Factor Experiment}

Before the RSM analysis, the factors and levels of the experiment should be selected according to the range of the individual factors. Under the same conditions, only one independent variable is adjusted, and its effect on the nonlinear amplitude is determined, as shown in Figure 5. If the number of cycles is small, then the launch energy is low, which makes it difficult to obtain harmonics at the receiving end. If the number of cycles is large, the wave of the first cycle propagates through the sample and is reflected, thereby interfering with the newly excited wave. Therefore, the measurements could be inaccurate. The effect of the cycle number on the amplitude is shown in Figure 5a. With an increasing number of cycles, the values of $A_{1}$ and $A_{2}$ also exhibit a rapid increase to reach maximum values at 11 cycles followed by a decrease. $A_{1}$ and $A_{2}$ mainly increase because of the increase in number of cycles and launch energy. However, since the test sample is thinner, nonlinearity of the pulse strings occurs due to overlap, and the trailing effect of the received 
signal should be minimized. The data fluctuate within the range from 7 to 11 pulse strings, which corresponds to a relatively small cycle number and a relatively stable measurement environment. Figure $5 b, c$ shows that both the output level and gain indicate amplification of the received signal. With an increasing signal, the amplitude value continuously increases. However, an excessive signal leads to an excessive voltage, which could damage the device, and the signal could become too large to receive the excessive amplitude value, which easily leads to distortion. Thus, to guarantee the signal stability, the step size of the output level and gain should be gradually increased.

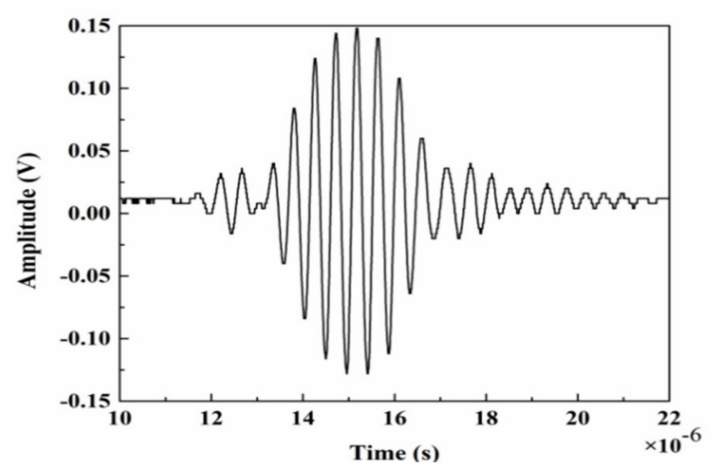

(a)

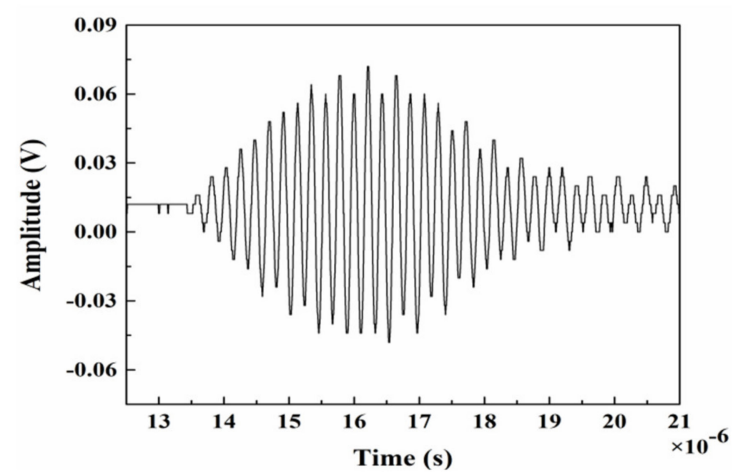

(b)

Figure 3. Lamb wave time-domain signal recorded by the oscilloscope: (a) Fundamental wave and (b) second harmonic.

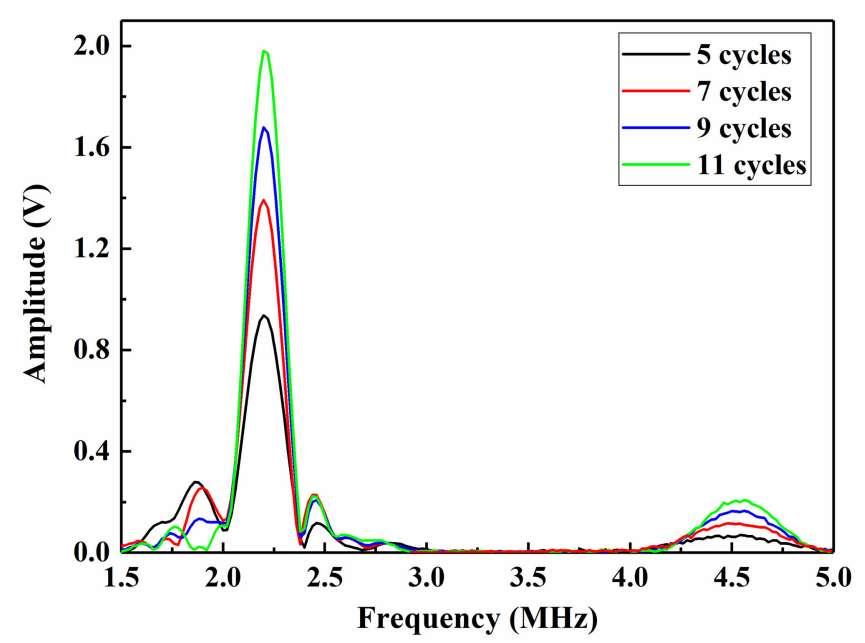

Figure 4. Frequency-domain signal during various cycles.

\subsection{Response Surface Model Analysis}

The number of sample points randomly selected via CCD in the experimental design space is given by Equation (9) [39]:

$$
N=2^{n}+2 n+\lambda_{0}
$$

where $N$ is the total number of experiments, $n$ is the number of independent variables, and $\lambda_{0}$ is the number of repeated experiments at the center point. Regarding this design, the factor number is 3 and $\lambda_{0}$ is 6 . Therefore, a total of 20 groups of training points are selected, and the DOE space of the three design parameters is constructed, as shown in Figure 6. The experimental results of CCD are listed in Table 2. 


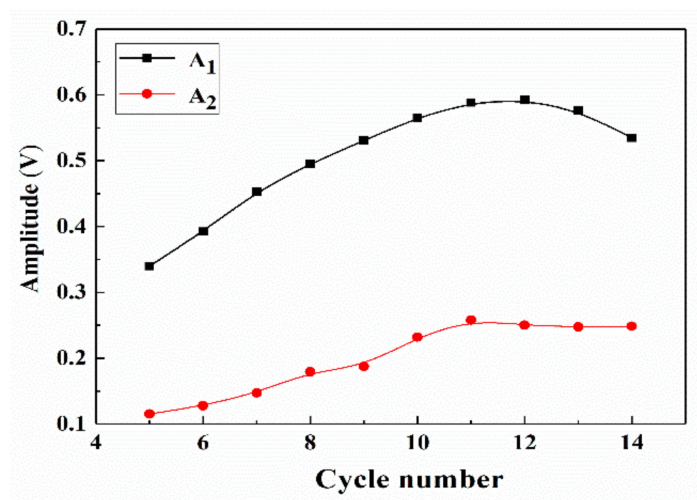

(a)

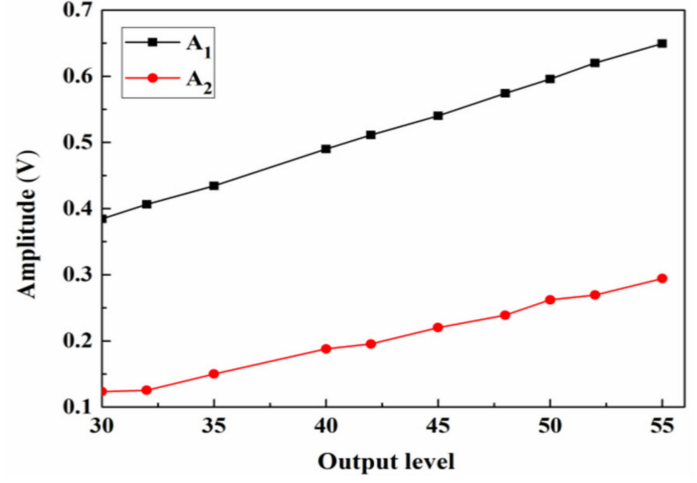

(b)

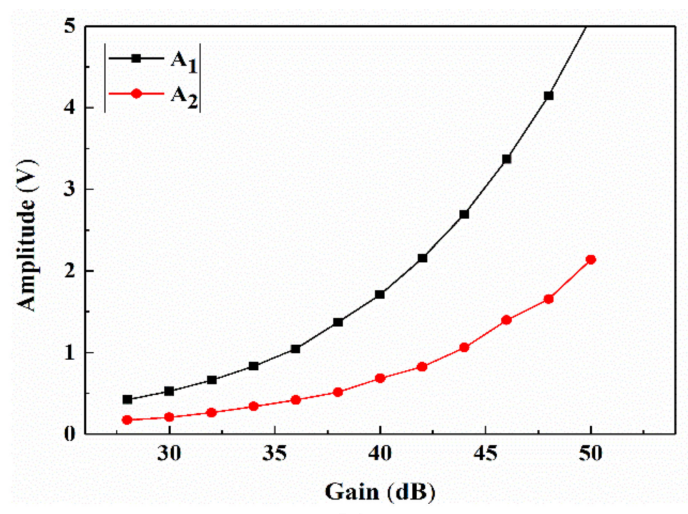

(c)

Figure 5. Single-factor experimental effect of the (a) cycle number, (b) output level, and (c) gain on $\mathrm{A}_{1}$ and $\mathrm{A}_{2}$.

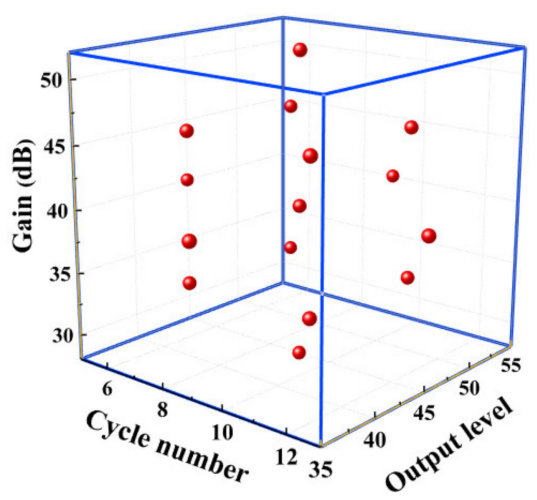

Figure 6. DOE space of the three design parameters and the selected training points.

An analysis of variance (ANOVA) [40] was employed to assess the significance and accuracy of the response surface model, and the results of the fitted quadratic polynomial regression model to response surface values $A_{1}$ and $A_{2}$ are listed in Table 3. ANOVA is also referred to as an F-test, and the F-value at the corresponding significance level was considered to assess the difference between sample points. When the F-value is higher, the fitted equation is more significant, and the fit is better. The $p$-value is the probability value under the corresponding F value, which reflects the conditional probability of the occurrence of extreme result $\mathrm{D}$ under the original hypothesis $\mathrm{H}$ (i.e., prob $(\mathrm{D} / \mathrm{H})$ ). High Fvalues and low $p$-values ensure the significance of the RSM model [41]. $p$-values of less than 0.05 demonstrate that the RSM model is significant, and a good fitting accuracy ensures the subsequent response surface design of the approximation model. Consequently, the model $p$-values for $A_{1}$ and $A_{2}$ are below 0.0001, which suggests that both RSM models are highly 
significant. Regarding the two models of $\mathrm{A}_{1}$ and $\mathrm{A}_{2}$, the F-values are 5498.52 and 353.71, respectively, which suggest that they are significant. The lack-of-fit F-values of 2.01 and 2.44, and the lack-of-fit $p$-values of 0.2314 and 0.1752 for $A_{1}$ and $A_{2}$, respectively, suggest that the two models are not significant $(p>0.05)$ relative to the pure error. A nonsignificant lack of fit is good, which indicates that the fitting degree of the two models is suitable, and the test error is small. In this case, $x_{1}, x_{2}, x_{3}, x_{1}^{2}, x_{3}{ }^{2}, x_{1 \times 3}$, and $x_{2 \times 3}$ of response $\mathrm{A}_{1}$ and $x_{1}$, $x_{2}, x_{3}, x_{1 \times 3}, x_{2 \times 3}$, and $x_{3}^{2}$ of response $\mathrm{A}_{2}$ are highly significant $(p<0.01)$, and these values indicate a great influence on responses $\mathrm{A}_{1}$ and $\mathrm{A}_{2}$, rather than simple linear relationships.

Table 2. Experimental results of CCD.

\begin{tabular}{|c|c|c|c|c|c|c|c|c|c|c|c|c|}
\hline \multirow[t]{2}{*}{ Run } & \multicolumn{3}{|c|}{ Coded } & \multicolumn{3}{|c|}{ Actual } & \multicolumn{2}{|c|}{$\begin{array}{c}\text { Actual Values } \\
\text { (V) }\end{array}$} & \multicolumn{2}{|c|}{$\begin{array}{c}\text { Predicted } \\
\text { Values (V) }\end{array}$} & \multicolumn{2}{|c|}{$\begin{array}{c}\text { Relative Errors } \\
(\%)\end{array}$} \\
\hline & $X_{1}$ & $X_{2}$ & $X_{3}$ & $x_{1}$ & $x_{2}$ & $x_{3}$ & $\mathbf{A}_{1}$ & $\mathbf{A}_{2}$ & $\mathbf{A}_{\mathbf{1}}{ }^{\prime}$ & $\mathbf{A}_{2}^{\prime}$ & $\delta \mathrm{A} 1$ & $\delta \mathrm{A} 2$ \\
\hline 1 & -1 & 1 & -1 & 7 & 50 & 34 & 0.1623 & 0.0987 & 0.1602 & 0.0939 & 1.31 & 5.07 \\
\hline 2 & 1 & -1 & 1 & 11 & 40 & 46 & 0.8260 & 0.4583 & 0.8298 & 0.4668 & -0.46 & -1.82 \\
\hline 3 & 1 & -1 & -1 & 11 & 40 & 34 & 0.1598 & 0.1086 & 0.1562 & 0.0997 & 2.30 & 8.97 \\
\hline 4 & 1 & 1 & -1 & 11 & 50 & 34 & 0.1965 & 0.1627 & 0.1912 & 0.1520 & 2.77 & 7.06 \\
\hline 5 & 2 & 0 & 0 & 13 & 45 & 40 & 0.4574 & 0.2695 & 0.4603 & 0.2802 & -0.63 & -3.83 \\
\hline 6 & -1 & 1 & 1 & 7 & 50 & 46 & 0.7521 & 0.4546 & 0.7574 & 0.4673 & -0.70 & -2.72 \\
\hline 7 & 0 & 0 & 0 & 9 & 45 & 40 & 0.3905 & 0.2507 & 0.3863 & 0.2468 & 1.09 & 1.60 \\
\hline 8 & 1 & 1 & 1 & 11 & 50 & 46 & 0.9845 & 0.6019 & 0.9855 & 0.5953 & -0.10 & 1.11 \\
\hline 9 & 0 & 0 & 0 & 9 & 45 & 40 & 0.3787 & 0.2386 & 0.3863 & 0.2468 & -1.97 & -3.31 \\
\hline 10 & 0 & 0 & 0 & 9 & 45 & 40 & 0.3878 & 0.2488 & 0.3863 & 0.2468 & 0.39 & 0.83 \\
\hline 11 & 0 & 2 & 0 & 9 & 55 & 40 & 0.4716 & 0.2918 & 0.4730 & 0.2984 & -0.30 & -2.20 \\
\hline 12 & -1 & -1 & 1 & 7 & 40 & 46 & 0.6122 & 0.3880 & 0.6192 & 0.4025 & -1.13 & -3.60 \\
\hline 13 & 0 & 0 & 0 & 9 & 45 & 40 & 0.3854 & 0.2596 & 0.3863 & 0.2468 & -0.23 & 5.20 \\
\hline 14 & 0 & 0 & -2 & 9 & 45 & 28 & 0.1674 & 0.1066 & 0.1734 & 0.1155 & -3.46 & -7.70 \\
\hline 15 & -1 & -1 & -1 & 7 & 40 & 34 & 0.1421 & 0.0949 & 0.1427 & 0.1053 & -0.42 & -9.85 \\
\hline 16 & 0 & 0 & 0 & 9 & 45 & 40 & 0.3835 & 0.2300 & 0.3863 & 0.2468 & -0.72 & -6.79 \\
\hline 17 & 0 & 0 & 0 & 9 & 45 & 40 & 0.3935 & 0.2567 & 0.3863 & 0.2468 & 1.86 & 4.03 \\
\hline 18 & 0 & 0 & 2 & 9 & 45 & 52 & 1.4520 & 0.8687 & 1.4443 & 0.8560 & 0.53 & 1.48 \\
\hline 19 & -2 & 0 & 0 & 5 & 45 & 40 & 0.2233 & 0.1724 & 0.2187 & 0.1579 & 2.10 & 9.21 \\
\hline 20 & 0 & -2 & 0 & 9 & 35 & 40 & 0.3029 & 0.1916 & 0.2998 & 0.1812 & 1.03 & 5.72 \\
\hline
\end{tabular}

The error statistical analysis results of the regression equations are provided in Table 4. The coefficient of variation (C.V.) values are $1.39 \%$ and $5.11 \%$ for $A_{1}$ and $A_{2}$, respectively, which are less than $10 \%$, which indicates a high accuracy and reliability of the two models. Adeq. Precision reflects the signal-to-noise ratio, and this value should be higher than 4 . Regarding the two models, the ratios of 286.028 and 73.321 are obtained, which suggests that the signal level is adequate. The two response surface models can be employed to navigate the DOE space. Furthermore, the R-squared values are 0.9998 and 0.9969 for $\mathrm{A}_{1}$ and $A_{2}$, respectively. When the multiple correlation coefficient $R^{2}$ is higher, the correlation is better. Based on Table 4, regarding the two models, the obtained $R^{2}$ values are greater than 0.99 , which indicates that $99 \%$ of the total variation in $A_{1}$ and $A_{2}$ can be attributed to the experimental variables, and the experimental values are highly similar to the predicted values. Additionally, the $R_{\text {pred }}{ }^{2}$ values are consistent with the $R_{\text {adj }}{ }^{2}$ values. This suggests that all empirical models contain significant terms. According to the statistical analysis of the above regression equations, the regression equation model is the most suitable for this study. 
Table 3. ANOVA results of the fitted quadratic regression models.

\begin{tabular}{|c|c|c|c|c|c|c|c|c|}
\hline \multirow[b]{2}{*}{ Source } & \multicolumn{4}{|c|}{ Response $\mathbf{A}_{1}$} & \multicolumn{4}{|c|}{ Response $\mathbf{A}_{2}$} \\
\hline & $\begin{array}{l}\text { Sum of } \\
\text { Squares }\end{array}$ & $\begin{array}{l}\text { Mean } \\
\text { Square }\end{array}$ & F-Value & $\begin{array}{c}p \text {-Value } \\
\text { Probability }>\text { F }\end{array}$ & $\begin{array}{l}\text { Sum of } \\
\text { Squares }\end{array}$ & $\begin{array}{l}\text { Mean } \\
\text { Square }\end{array}$ & $\begin{array}{c}\text { F- } \\
\text { Value }\end{array}$ & $\begin{array}{c}p \text {-Value } \\
\text { Probability }> \\
\text { F }\end{array}$ \\
\hline Model & 2.05 & 0.23 & 5498.52 & $\begin{array}{c}<0.0001 \\
\text { significant }\end{array}$ & 0.69 & 0.076 & 353.71 & $\begin{array}{c}<0.0001 \\
\text { significant }\end{array}$ \\
\hline $\begin{array}{c}x_{1-}^{-} \\
\text {Cycle } \\
\text { number }\end{array}$ & 0.058 & 0.058 & 1409.22 & $<0.0001$ & 0.015 & 0.015 & 69.31 & $<0.0001$ \\
\hline $\begin{array}{c}x_{2^{-}} \\
\text {Output } \\
\text { level }\end{array}$ & 0.030 & 0.03 & 724.18 & $<0.0001$ & 0.014 & 0.014 & 63.49 & $<0.0001$ \\
\hline $\begin{array}{l}x_{3} \text {-Gain } \\
(\mathrm{dB})\end{array}$ & 1.61 & 1.61 & 38998 & $<0.0001$ & 0.55 & 0.55 & 2538.12 & $<0.0001$ \\
\hline$x_{1 \times 2}$ & $1.54 \times 10^{-4}$ & $1.54 \times 10^{-4}$ & 3.72 & 0.0827 & $2.03 \times 10^{-3}$ & $2.03 \times 10^{-3}$ & 9.38 & 0.0120 \\
\hline$x_{1 \times 3}$ & 0.019 & 0.019 & 469.29 & $<0.0001$ & $2.45 \times 10^{-3}$ & $2.45 \times 10^{-3}$ & 11.32 & 0.0072 \\
\hline$x_{2 \times 3}$ & $7.29 \times 10^{-3}$ & $7.29 \times 10^{-3}$ & 176.04 & $<0.0001$ & $2.90 \times 10^{-3}$ & $2.90 \times 10^{-3}$ & 13.42 & 0.0044 \\
\hline$x_{1}^{2}$ & $3.44 \times 10^{-3}$ & $3.44 \times 10^{-3}$ & 83.01 & $<0.0001$ & $1.21 \times 10^{-3}$ & $1.21 \times 10^{-3}$ & 5.58 & 0.0397 \\
\hline$x_{2}^{2}$ & $2.54 \times 10^{-8}$ & $2.54 \times 10^{-8}$ & $\begin{array}{c}6.15 \times \\
10^{-4}\end{array}$ & 0.9807 & $7.61 \times 10^{-5}$ & $7.61 \times 10^{-5}$ & 0.35 & 0.5660 \\
\hline$x_{3}^{2}$ & 0.28 & 0.28 & 6776.11 & $<0.0001$ & 0.09 & 0.09 & 415.42 & $<0.0001$ \\
\hline Residual & $4.14 \times 10^{-4}$ & $4.14 \times 10^{-5}$ & & & $2.16 \times 10^{-3}$ & $2.16 \times 10^{-4}$ & & \\
\hline $\begin{array}{l}\text { Lack of } \\
\text { Fit }\end{array}$ & $2.76 \times 10^{-4}$ & $5.53 \times 10^{-5}$ & 2.01 & $\begin{array}{c}0.2314 ; \\
\text { not significant }\end{array}$ & $1.53 \times 10^{-3}$ & $3.06 \times 10^{-3}$ & 2.44 & $\begin{array}{c}0.1752 ; \\
\text { not significant }\end{array}$ \\
\hline $\begin{array}{l}\text { Pure } \\
\text { Error }\end{array}$ & $1.38 \times 10^{-4}$ & $2.75 \times 10^{-5}$ & & & $6.28 \times 10^{-4}$ & $1.26 \times 10^{-4}$ & & \\
\hline $\begin{array}{l}\text { Cor } \\
\text { Total }\end{array}$ & 2.05 & & & & 0.69 & & & \\
\hline
\end{tabular}

Table 4. Error statistical analysis of the regression equations.

\begin{tabular}{ccccccccc}
\hline Response & $\begin{array}{c}\text { Standard } \\
\text { Deviation }\end{array}$ & Mean & C.V. (\%) & PRESS & R-Squared & $\begin{array}{c}\text { Adjusted } \\
\text { R- } \\
\text { Squared }\end{array}$ & $\begin{array}{c}\text { Predicted } \\
\text { R-Squared }\end{array}$ & $\begin{array}{c}\text { Adeq. } \\
\text { Precision }\end{array}$ \\
\hline $\mathrm{A}_{1}$ & $6.435 \times 10^{-3}$ & 0.46 & 1.39 & $2.51 \times 10^{-3}$ & 0.9998 & 0.9996 & 0.9988 \\
$\mathrm{~A}_{2}$ & 0.015 & 0.29 & 5.11 & 0.014 & 0.9969 & 0.9941 & 0.9803 & 73.321 \\
\hline
\end{tabular}

The final second-order polynomial equations in terms of the coded factors are

$$
\begin{aligned}
& \mathrm{A}_{1}=\left[\begin{array}{llll}
1 & X_{1} & X_{2} & X_{3}
\end{array}\right]\left[\begin{array}{cccc}
0.39 & 0.03 & 0.0215 & 0.16 \\
0.03 & -0.012 & 2.1935 \times 10^{-3} & 0.0245 \\
0.0215 & 2.1935 \times 10^{-3} & 3.182 \times 10^{-5} & 0.015 \\
0.16 & 0.0245 & 0.015 & 0.11
\end{array}\right]\left[\begin{array}{c}
1 \\
X_{1} \\
X_{2} \\
X_{3}
\end{array}\right] \\
& \mathrm{A}_{2}=\left[\begin{array}{llll}
1 & X_{1} & X_{2} & X_{3}
\end{array}\right]\left[\begin{array}{cccc}
0.25 & 0.0155 & 0.0145 & 0.095 \\
0.0155 & -6.927 \times 10^{-3} & 0.008 & 0.0085 \\
0.0145 & 0.008 & -1.740 \times 10^{-3} & 0.0095 \\
0.095 & 0.0085 & 0.0095 & 0.06
\end{array}\right]\left[\begin{array}{c}
1 \\
X_{1} \\
X_{2} \\
X_{3}
\end{array}\right]
\end{aligned}
$$

The final second-order polynomial equations in terms of the actual factors are

$$
\begin{gathered}
\mathrm{A}_{1}=\left[\begin{array}{llll}
1 & x_{1} & x_{2} & x_{3}
\end{array}\right]\left[\begin{array}{cccc}
5.5355 & -0.0506 & -0.0178 & -0.1320 \\
-0.0506 & -2.9233 \times 10^{-5} & 2.1937 \times 10^{-4} & 2.0536 \times 10^{-3} \\
-0.0178 & 2.1937 \times 10^{-4} & 1.2727 \times 10^{-5} & 0.5031 \times 10^{-3} \\
-0.1320 & 2.0536 \times 10^{-3} & 0.5031 \times 10^{-3} & 2.9346 \times 10^{-3}
\end{array}\right]\left[\begin{array}{c}
1 \\
x_{1} \\
x_{2} \\
x_{3}
\end{array}\right] \\
\mathrm{A}_{2}=\left[\begin{array}{llll}
1 & x_{1} & x_{2} & x_{3}
\end{array}\right]\left[\begin{array}{cccc}
3.2970 & -0.04171 & -0.01379 & -0.07179 \\
-0.04171 & -1.7318 \times 10^{-3} & 0.7956 \times 10^{-3} & 0.7286 \times 10^{-3} \\
-0.01379 & 0.7956 \times 10^{-3} & -6.9591 \times 10^{-5} & 3.1729 \times 10^{-4} \\
-0.07179 & 0.7286 \times 10^{-3} & 3.1729 \times 10^{-4} & 1.6597 \times 10^{-3}
\end{array}\right]\left[\begin{array}{c}
1 \\
x_{1} \\
x_{2} \\
x_{3}
\end{array}\right]
\end{gathered}
$$


The internally studentized residuals are the values obtained by dividing the residuals by their standard deviations, which are considered to intuitively assess whether the assumption that the error terms obey a normal distribution is true. If the assumption holds true, then the distribution of the internally studentized residuals should also obey a normal distribution. The internally studentized residuals are the statistics of the abnormal point test. Figures 7-9 show a comparison of the predicted and actual values, the residual normal probability distribution, and the internal residual and predicted value distributions. The comparison of the experimental and predicted values reveals that a high degree of similarity exists between the actual and predicted values. Furthermore, the normal probability distribution of the residuals exhibits near-linearity, and irregular distributions of the internally studentized residuals and predicted values are obtained. Based on Figures 7-9, the response surface models of $A_{1}$ and $A_{2}$ attain good adaptability in nonlinear ultrasonic nondestructive detection.

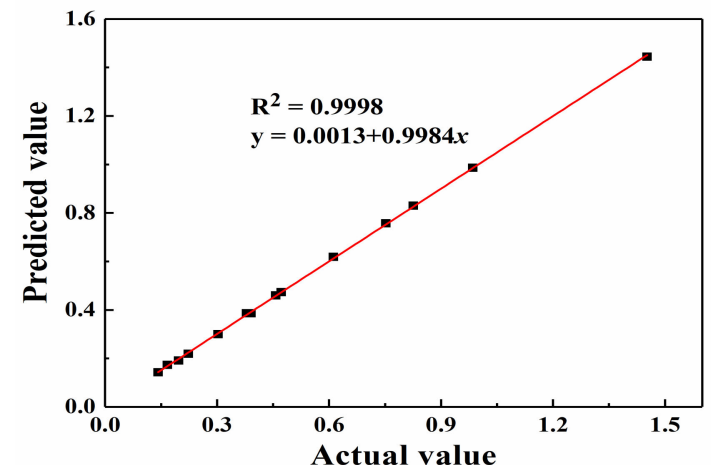

(a)

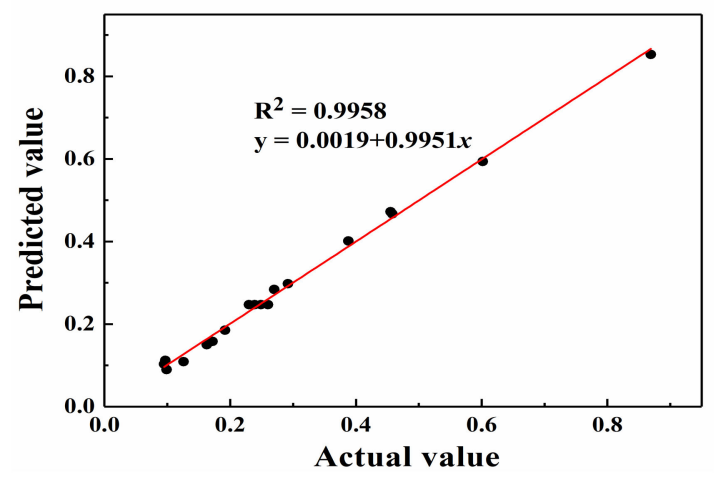

(b)

Figure 7. Comparison of the predicted and actual values: (a) $A_{1}$ and (b) $A_{2}$.

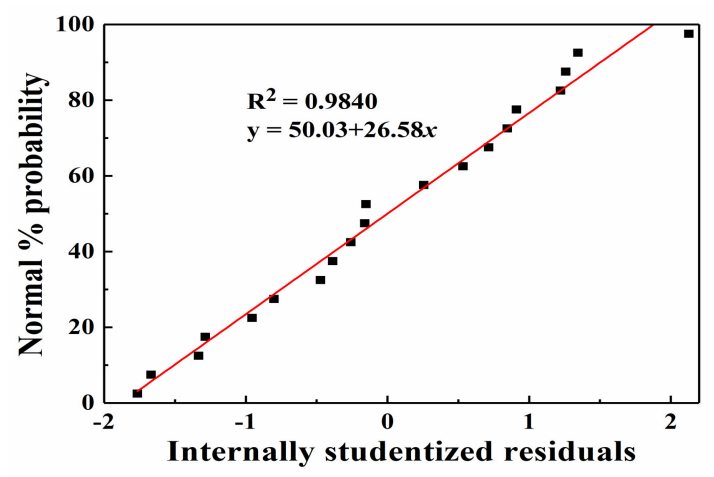

(a)

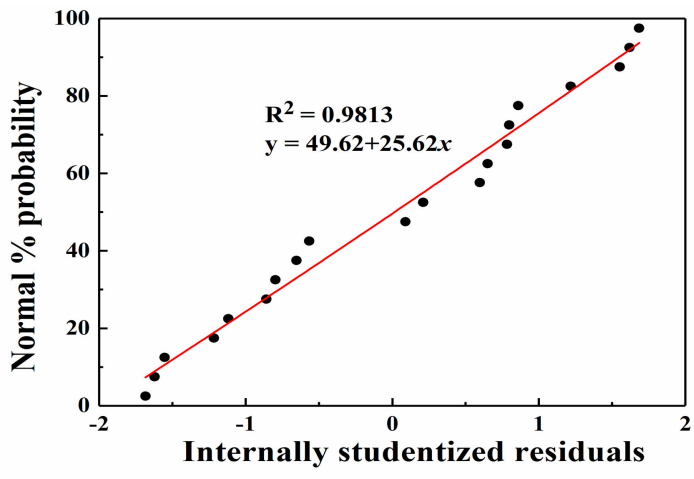

(b)

Figure 8. Normal probability distribution of the residuals: (a) $A_{1}$ and (b) $A_{2}$.

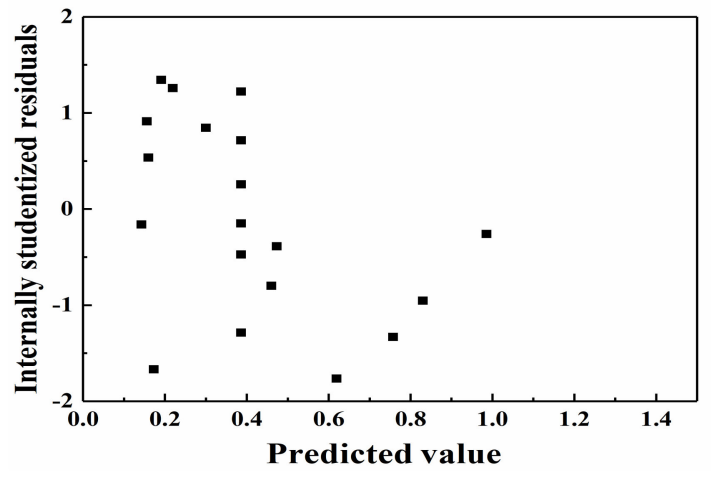

(a)

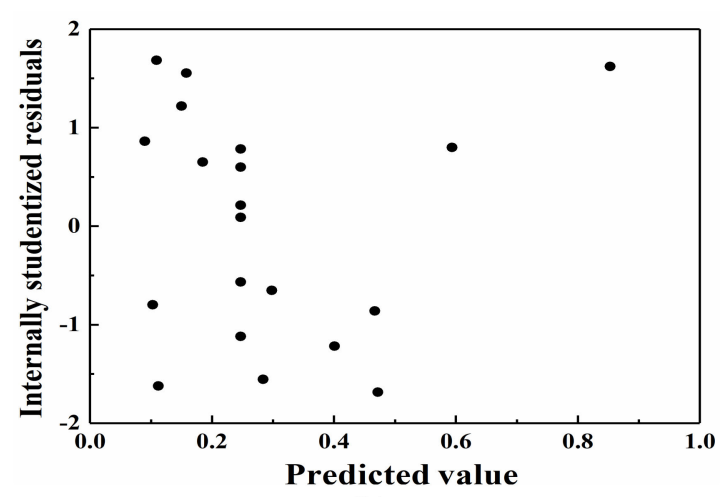

(b)

Figure 9. Distribution of the predicted values and internally studentized residuals: (a) $A_{1}$ and (b) $A_{2}$. 


\section{Results and Discussion}

To more intuitively analyze the effect of each factor, determine their mutual interactions with $A_{1}$ and $A_{2}$, and characterize the shape of the response surface function, 3D response plots are generated according to the quadratic polynomial regression equations, as shown in Figures 10 and 11. These figures demonstrate the interaction effect of the independent variables with $A_{1}$ and $A_{2}$ when a certain factor remains fixed at the same central value.

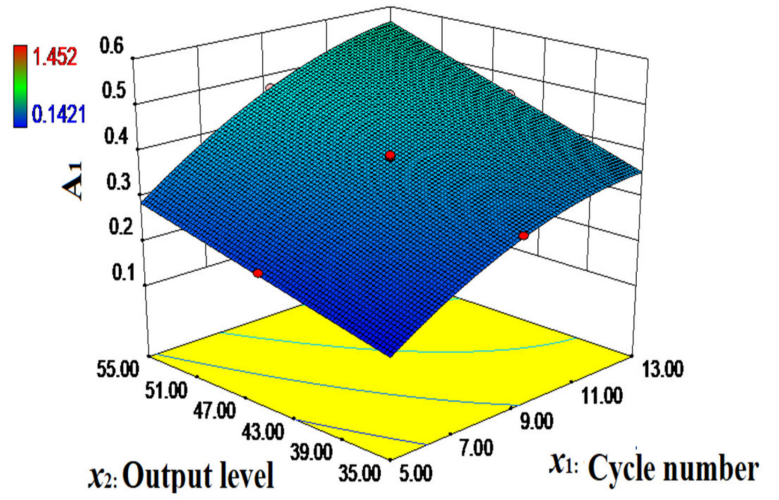

(a)

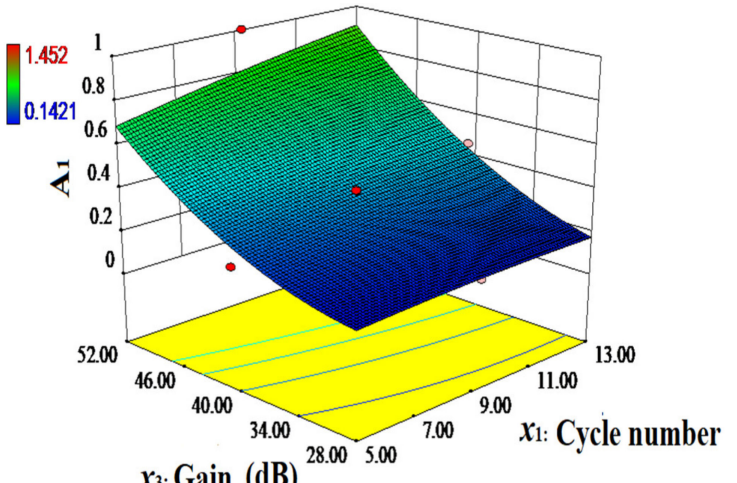

(b)

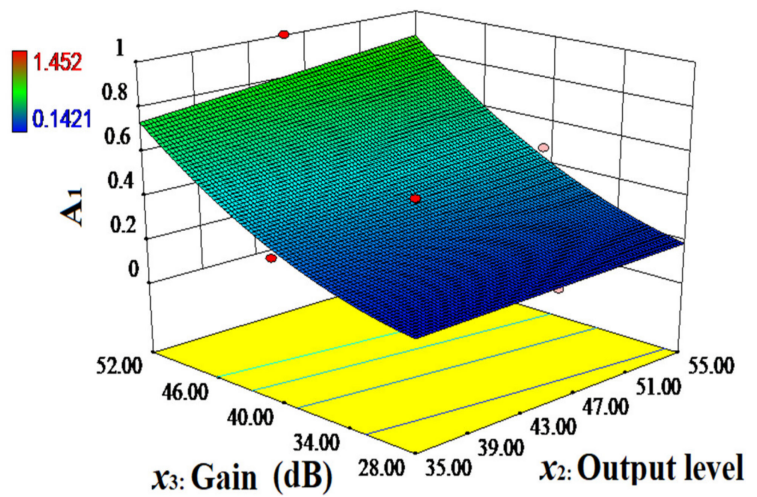

(c)

Figure 10. Three-dimensional (3D) response plots: (a) Cycle number $\left(x_{1}\right)$ and output level $\left(x_{2}\right)$, (b) cycle number $\left(x_{1}\right)$ and gain $\left(x_{3}\right)$, (c) output level $\left(x_{2}\right)$ and gain $\left(x_{3}\right)$, and their mutual interactions with $\mathrm{A}_{1}$.

Figures 10 and 11 show that when the slope of the curve is steeper, the effect of the independent variables on the amplitude is more significant. Moreover, when the slope is smoother, the effect is less significant. The effects of the cycle number, output level, and gain on amplitudes $A_{1}$ and $A_{2}$ of the nonlinear ultrasonic waves are significant with steep curves. The response surface plots of the cycle number and output level on $\mathrm{A}_{1}$ and $\mathrm{A}_{2}$ exhibit open downward convex surfaces. This indicates that the response values are extremely high within the range of the experimental factors, and the optimal values of the cycle number and output level are $8 \sim 10$ and 40 45, respectively. The interactions between the number of cycles and gain, and between the output level and gain impose a strong effect on the nonlinear ultrasonic wave amplitudes $A_{1}$ and $A_{2}$, which results in high-density contour lines. The interaction between the number of cycles and output level imposes no significant effect on nonlinear ultrasonic wave amplitude $\mathrm{A}_{1}$, and the contour lines are not dense. The interaction between the number of cycles and output level exerts a secondary significant effect on nonlinear ultrasound amplitude $\mathrm{A}_{2}$, and the contour lines are not dense, which is consistent with the variance analysis results. 


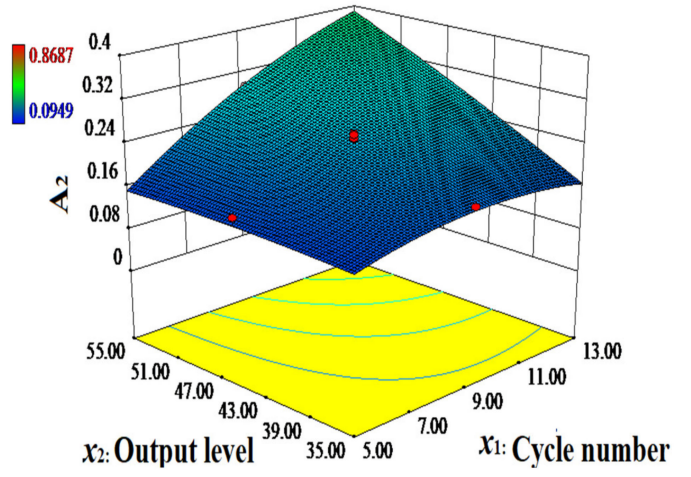

(a)

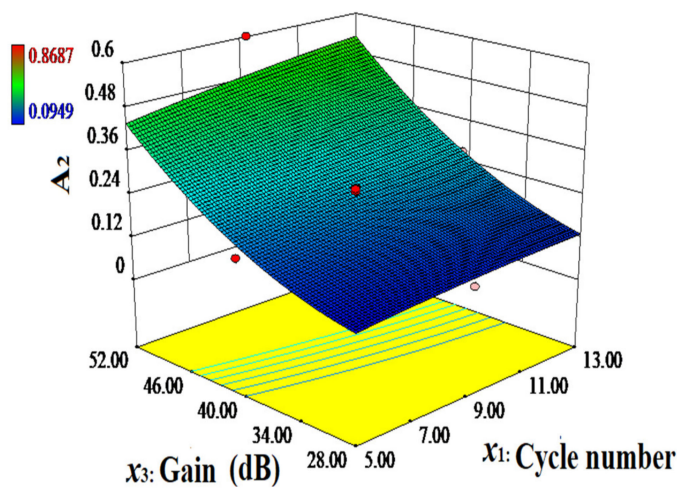

(b)

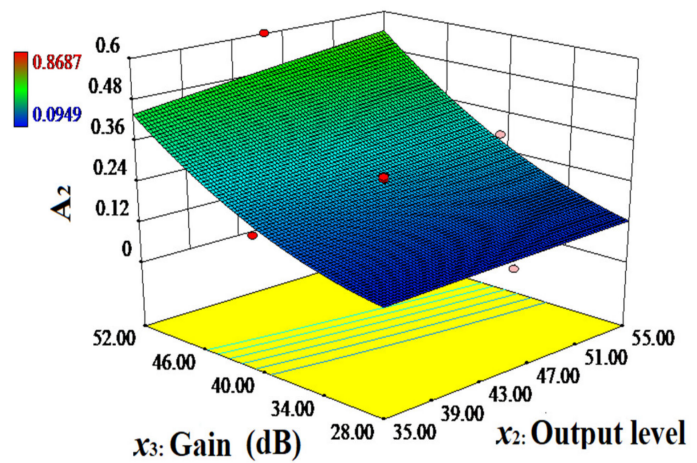

(c)

Figure 11. Three-dimensional (3D) response plots: (a) Cycle number $\left(x_{1}\right)$ and output level $\left(x_{2}\right)$, (b) cycle number $\left(x_{1}\right)$ and gain $\left(x_{3}\right)$, (c) output level $\left(x_{2}\right)$ and gain $\left(x_{3}\right)$, and their mutual interactions with $\mathrm{A}_{2}$.

Furthermore, the second-order polynomial response surface model is a conic function. Therefore, a maximum, minimum, or saddle value exists. Thus, to further determine the optimal point, we obtain the derivative with respect to the actual value of each independent variable $\left(x_{i}\right)$ by setting the quadratic nonlinear regression model (i.e., Equations (12) and (13)) to zero and then applying the MATLAB software to solve these equations.

The obtained equations are

$$
\left[\begin{array}{ccc}
-5.8466 \times 10^{-3} & 4.3875 \times 10^{-4} & 4.1073 \times 10^{-3} \\
4.3875 \times 10^{-4} & 2.5455 \times 10^{-6} & 1.0063 \times 10^{-3} \\
4.1073 \times 10^{-3} & 1.0063 \times 10^{-3} & 5.8691 \times 10^{-3}
\end{array}\right]\left[\begin{array}{l}
x_{1} \\
x_{2} \\
x_{3}
\end{array}\right]=\left[\begin{array}{l}
0.1012 \\
0.0357 \\
0.2641
\end{array}\right]
$$

The solutions of the model relative to the actual values of $\mathrm{A}_{1}$ are $x_{1}=8.2531, x_{2}=43.6944$, and $x_{3}=31.7245$.

$$
\left[\begin{array}{ccc}
-3.4636 \times 10^{-3} & 1.5913 \times 10^{-3} & 1.4573 \times 10^{-3} \\
1.5913 \times 10^{-3} & -1.3918 \times 10^{-4} & 6.3458 \times 10^{-4} \\
1.4573 \times 10^{-3} & 6.3458 \times 10^{-4} & 3.3193 \times 10^{-3}
\end{array}\right]\left[\begin{array}{c}
x_{1} \\
x_{2} \\
x_{3}
\end{array}\right]=\left[\begin{array}{c}
0.08343 \\
0.02759 \\
0.1436
\end{array}\right]
$$

The solutions of the model relative to the actual values of $\mathrm{A}_{2}$ are $x_{1}=8.3877, x_{2}=41.7520$, and $x_{3}=31.5943$.

Considering operational convenience, the simultaneous detection of $A_{1}$ and $A_{2}$ under the same conditions to ensure the reliability of the response surface results given the above optimized conditions is preferable. The optimal experimental parameters regarding the response surface include approximately 8 cycles, an output level of 42 , and a gain of $32 \mathrm{~dB}$. Under these conditions, the averaged $\mathrm{A}_{1}$ and $\mathrm{A}_{2}$ values based on the three parallel tests are 0.1502 and 0.0976 , with mean errors of $0.31 \%$ and $4.85 \%$, respectively. This work indicates 
that the RSM models are feasible and significant for predicting $A_{1}$ and $A_{2}$ under different cycle numbers, output level and gain in the nonlinear ultrasonic detection system.

To further verify that the RSM model satisfies the requirements of the amplitude, we randomly selected ten training points outside the response surface level and substituted them into Equations (12) and (13) to compare the accuracy of the predicted values and experimental data. The calculation results for the corresponding nonlinear coefficient $\beta^{\prime}$ are listed in Table 5, and the relative errors in the response values $A_{1}, A_{2}$, and $\beta^{\prime}$ are below $10 \%$. The experimentally measured values match the predicted values from the regression model, which indicates that the response surface model fits the actual situation accurately and that the RSM application to the experimental parameters of the nonlinear ultrasonic amplitude is optimized. The established quadratic nonlinear regression model is accurate and effective, and the experimental fitting effect is suitable, which yields a certain practical value.

Table 5. Comparison of the predicted values with the RSM and the experimental values.

\begin{tabular}{|c|c|c|c|c|c|c|c|c|c|}
\hline \multirow{2}{*}{ Cycle Number } & \multirow{2}{*}{ Output Level } & \multirow{2}{*}{ Gain } & \multicolumn{2}{|c|}{ Actual Values } & \multicolumn{2}{|c|}{ Predicted Values } & \multicolumn{3}{|c|}{ Relative Errors } \\
\hline & & & $A_{1}(V)$ & $A_{2}(V)$ & $A_{1}{ }^{\prime}(V)$ & $A_{2}^{\prime}(V)$ & $\delta_{\mathrm{A} 1}(\%)$ & $\delta_{\mathrm{A} 2}(\%)$ & $\Delta \beta^{\prime}(\%)$ \\
\hline 8 & 36 & 50 & 0.9396 & 0.5967 & 0.9706 & 0.5825 & -3.20 & 1.39 & 8.20 \\
\hline 8 & 36 & 44 & 0.4759 & 0.3207 & 0.4854 & 0.3059 & -1.96 & 4.46 & 8.67 \\
\hline 10 & 52 & 50 & 1.5298 & 0.9222 & 1.4118 & 0.8423 & 8.36 & 9.45 & -6.78 \\
\hline 10 & 48 & 44 & 0.7148 & 0.4355 & 0.7281 & 0.4453 & -1.83 & -2.24 & 1.44 \\
\hline 10 & 46 & 42 & 0.5480 & 0.3394 & 0.5505 & 0.3408 & -0.46 & -0.25 & 0.68 \\
\hline 10 & 38 & 42 & 0.4642 & 0.286 & 0.4617 & 0.2707 & 0.54 & 7.05 & 5.91 \\
\hline 8 & 54 & 30 & 0.1463 & 0.075 & 0.1417 & 0.0672 & 3.25 & --3.05 & -9.05 \\
\hline 12 & 38 & 44 & 0.6108 & 0.3254 & 0.6607 & 0.3542 & -7.55 & -6.75 & 9.11 \\
\hline 6 & 36 & 44 & 0.3759 & 0.3003 & 0.3767 & 0.2755 & -0.20 & 7.43 & 7.86 \\
\hline 10 & 36 & 42 & 0.4427 & 0.2500 & 0.4395 & 0.2520 & 0.72 & 1.01 & -0.43 \\
\hline
\end{tabular}

Under the same conditions and within a certain range of the input voltage, the output level of the gated amplifier ranges from 36 to 48 . By inputting different excitation voltages, a series of $\mathrm{A}_{1}{ }^{2}$ and $\mathrm{A}_{2}$ is generated, as shown in Figure 12. The relationship curve of $\mathrm{A}_{1}{ }^{2}$ and $\mathrm{A}_{2}$ can be obtained based on the measured data via polynomial fitting (i.e., $y_{1}=0.45305+0.12188 x_{1}+0.12188 x_{1}^{2}$ ) and the correlation coefficient is 0.9935 . Compared to the predicted values, the data fitting relationship curve of the response surface equation is $y_{2}=0.18316+0.50948 x_{2}-0.09045 x_{2}{ }^{2}$, and the correlation coefficient reaches 0.9997 , while the slope of the linear fitting is $\beta^{\prime}$. When the material properties and Lamb wave propagation distance remain constant, $\beta^{\prime}$ is a constant value, which indicates that the nonlinear response of the ultrasonic detection system in the experiment is stable and does not change with the excitation signal voltage. This further confirms that the nonlinear response is not caused by the external environment but by the interaction between the ultrasonic wave and nonlinear source in the specimen.

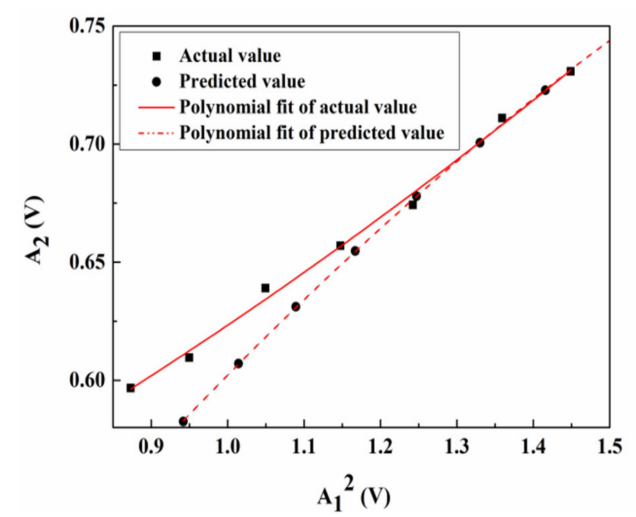

Figure 12. Ratio of $\mathrm{A}_{2}$ to $\mathrm{A}_{1}^{2}$ with increasing excitation voltage. 


\section{Conclusions}

Regression models that describe nonlinear ultrasonic amplitudes $\mathrm{A}_{1}$ and $\mathrm{A}_{2}$ and the relationship among the cycle number, output level, and gain were obtained via $\mathrm{CCD}$. The reliability of these response surface models was verified through ANOVA, error statistical analysis and normal probability distribution determination of the residuals. The results revealed that the models were reliable and precisely predicted amplitudes $A_{1}$ and $A_{2}$. The influence of these three factors on $A_{1}$ and $A_{2}$ and the interaction between the cycle number and both the output level and gain were significant. Regarding the response surface optimization, the values of the cycle number, output level, and gain were 8,42 and $32 \mathrm{~dB}$, respectively. Under these conditions, the average $\mathrm{A}_{1}$ and $\mathrm{A}_{2}$ values based on three parallel tests were 0.1502 and 0.0976 , with mean errors of $0.31 \%$ and $4.85 \%$, respectively. To further verify that the RSM model could reflect the requirements of the amplitude, we randomly selected ten points outside the response surface level. The relative errors in $A_{1}, A_{2}$, and $\beta^{\prime}$ were below $10 \%$, which indicates that the application of the response surface analysis method in nonlinear amplitude ultrasonic nondestructive testing could help determine the optimal process parameters and effectively reduce the challenge of empirically setting the experimental conditions, which could represent a starting point for further studies. In addition, the RSM model may be a promising way to predict $A_{1}$ and $A_{2}$ among nonlinear Lamb wave detection system parameters under different conditions and to study the interaction among all factors, which suggests a method for the optimization and quantitative assessment of CFRP laminate damage. The optimized conditions determined with the RAM-5000 SNAP detection system could also be employed to detect other materials, such as metals and woven composites, and have good applicability for other detection distances. In addition, the optimized conditions could be directly adopted in the mixed-frequency detection of material damage. Furthermore, this method provides the possibility to accurately monitor the structural health of composite materials.

Author Contributions: Methodology, Z.Y. and Y.T.; supervision, C.L. and Y.D.; validation, Z.Y. and Y.D.; writing original draft, Z.Y.; revision, Z.Y., Y.T. and Y.D., funding acquisition, C.L. and Y.T. All authors have read and agreed to the published version of the manuscript.

Funding: This work was financially supported by the National Science Foundation of China (No. U1833116) and the China Postdoctoral Science Foundation Funded Project (No. 2018M642775).

Institutional Review Board Statement: Not applicable.

Informed Consent Statement: Not applicable.

Data Availability Statement: No new data were created or analyzed in this study. Data sharing is not applicable to this article.

Conflicts of Interest: The authors declare no conflict of interest.

\section{References}

1. Hegde, S.; Shenoy, B.S.; Chethan, K.N. Review on carbon fiber reinforced polymer (CFRP) and their mechanical performance. Mater. Today Proc. 2019, 19, 658-662. [CrossRef]

2. Rajkumar, D.; Jeyaprakash, N.; Yang, C.H.; Sivasankaran, S. Optimization of Drilling Process on Carbon-Fiber Reinforced Plastics Using Genetic-Algorithm. Surf. Rev. Lett. 2021, 28, 2050056.

3. Karataş, M.A.; Gökkaya, H. A review on machinability of carbon fiber reinforced polymer (CFRP) and glass fiber reinforced polymer (GFRP) composite materials. Defin. Technol. 2018, 14, 318-326. [CrossRef]

4. Forintos, N.; Czigany, T. Multifunctional application of carbon fiber reinforced polymer composites: Electrical properties of the reinforcing carbon fibers-A short review. Compos. Part B Eng. 2019, 162, 331-343. [CrossRef]

5. Guo, J.G.; Gao, X.R.; Toma, E.; Netzelmann, U. Anisotropy in carbon fiber reinforced polymer (CFRP) and its effect on induction thermography. NDT E Int. 2017, 91, 1-8. [CrossRef]

6. Haider, M.F.; Yasmeen, F.; Haider, M.M. Micromechanics model for predicting anisotropic electrical conductivity of carbon fiber composite materials. AIP Conf. Proc. 2016, 1754, 3790-3797.

7. Rozylo, P.; Ferdynus, M.; Debski, H.; Samborski, S. Progressive Failure Analysis of Thin-Walled Composite Structures Verified Experimentally. Materials 2020, 13, 1138. [CrossRef] 
8. Fabbrocino, F.; Funari, M.F.; Greco, F. Dynamic crack growth based on moving mesh method. Compos. Part B Eng. 2019, 174, 107053. [CrossRef]

9. Alabtah, F.G.; Mahdi, E. The effect of sizing optimization on the interface between high strength steel and fiber reinforced composite. Compos. Struct. 2021, 113740. [CrossRef]

10. Hu, C.; Huang, G.; Li, C. Experimental and Numerical Study of Low-Velocity Impact and Tensile after Impact for CFRP Laminates Single-Lap Joints Adhesively Bonded Structure. Materials 2021, 14, 1016. [CrossRef]

11. Gliszczynski, A.; Bogenfeld, R.; Degenhardt, R.; Kubiak, T. Corner impact and compression after impact (CAI) of thin-walled composite profile-an experimental study. Compos. Struct. 2020, 248, 112502. [CrossRef]

12. Zhu, Y.; Zeng, X.; Deng, M. Mode selection of nonlinear lamb wave based on approximate phase velocity matching. NDT E Int. 2019, 102, 295-303. [CrossRef]

13. Solodov, I.; Wackerl, J.; Pfleiderer, K. Nonlinear self-modulation and subharmonic acoustic spectroscopy for damage detection and location. Appl. Phys. Lett. 2004, 84, 5386-5388. [CrossRef]

14. Li, W.B.; Xu, Y.R.; Hu, N. Impact damage detection in composites using a guided wave mixing technique. Meas. Sci. Technol. 2020, 31, 014001. [CrossRef]

15. She, H.; Li, C.; Tang, Q. Veering and merging analysis of nonlinear resonance frequencies of an assembly bladed disk system. J. Sound Vib. 2021, 493, 115818. [CrossRef]

16. Yelve, N.P.; Mitra, M.; Mujumdar, P.M. Detection of stiffener disbonding in a stiffened aluminium panel using nonlinear Lamb wave. Appl. Acoust. 2015, 89, 267-272. [CrossRef]

17. Sun, X.; Liu, X.; Liu, Y. Simulations on Monitoring and Evaluation of Plasticity-Driven Material Damage Based on Second Harmonic of $\mathrm{S}_{0}$ Mode Lamb Waves in Metallic Plates. Materials 2017, 10, 827. [CrossRef]

18. Li, W.B.; Hu, S.; Deng, M.X. Combination of Phase Matching and Phase-Reversal Approaches for Thermal Damage Assessment by Second Harmonic Lamb Waves. Materials 2018, 11, 1961. [CrossRef] [PubMed]

19. Cantrell, J.H.; Yost, W.T. Nonlinear ultrasonic characterization of fatigue microstructures. Int. J. Fatigue 2001, 23, 487-490. [CrossRef]

20. Dirik, H.; Yalinkaya, T. Crack Path and Life Prediction Under Mixed Mode Cyclic Variable Amplitude Loading Through XFEM. Int. J. Fatigue 2018, 114, 34-50. [CrossRef]

21. Li, W.B.; Xu, Y.R.; Hu, N. Numerical and experimental investigations on second-order combined harmonic generation of Lamb wave mixing. AIP Adv. 2020, 10, 045119. [CrossRef]

22. Yang, Y.; Ng, C.T.; Kotousov, A. Second-order harmonic generation of Lamb wave in prestressed plates. J. Sound Vib. 2019, 460, 114903. [CrossRef]

23. Jiao, J.P.; Meng, X.J.; He, C.F. Nonlinear Lamb wave-mixing technique for micro-crack detection in plates. NDT E Int. 2017, 85, 63-71.

24. Tie, Y.; Zhang, Q.S.; Hou, Y.L. Impact damage assessment in orthotropic CFRP laminates using nonlinear Lamb wave: Experimental and numerical investigations. Compos. Struct. 2020, 236, 111869. [CrossRef]

25. Yang, Y.; Ng, C.T.; Kotousov, A. Second harmonic generation at fatigue cracks by low-frequency Lamb waves: Experimental and numerical studies. Mech. Syst. Signal. Process. 2018, 99, 760-773. [CrossRef]

26. Carboni, M.; Gianneo, A.; Giglio, M.A. Lamb waves based statistical approach to structural health monitoring of carbon fiber reinforced polymer composites. Ultrasonics 2015, 60, 51-64. [CrossRef] [PubMed]

27. Ramazani, A.; Abbasi, M.; Prahl, U. Failure analysis of DP600 steel during the cross-die test. Comput. Mater. Sci. 2012, 64, 101-105. [CrossRef]

28. Fekih, S.; Albedah, A.; Benyahia, F.; Belhouari, M.; Bouiadjra, B.B. Optimisation of the sizes of bonded composite repair in aircraft structures. Mater. Design 2012, 41, 171-176. [CrossRef]

29. Tie, Y.; Hou, Y.L.; Li, C.; Meng, L. Optimization for maximizing the impact-resistance of patch repaired CFRP laminates using a surrogate-based model. Int. J. Mech. Sci. 2020, 172, 105407. [CrossRef]

30. Liu, H.; Yin, Z.H.; Zhang, Q. Mathematical modeling of bovine hides swelling behavior by response surface methodology for minimization of sulfide pollution in leather manufacture. J. Clean. Prod. 2019, 237, 117800. [CrossRef]

31. Oberoi, D.P.S.; Sogi, D.S. Utilization of watermelon pulp for lycopene extraction by response surface methodology. Food Chem. 2017, 232, 316-621. [CrossRef]

32. Zhang, J.F.; Li, S.Y.; Xuan, F.Z. Effect of plastic deformation on nonlinear ultrasonic response of austenitic stainless steel. Mater. Sci. Eng. A 2015, 622, 146-152. [CrossRef]

33. Jhang, K.Y. Nonlinear ultrasonic techniques for nondestructive assessment of micro damage in material: A review. Int. J. Precis. Eng. Manuf. 2009, 10, 123-135. [CrossRef]

34. Aslam, M.; Nagarajan, P.; Remanan, M. Defect Localization Using Nonlinear Lamb Wave Mixing Technique. J. Nondestruct. Eval. 2021, 40, 16. [CrossRef]

35. Amura, M.; Meo, M.; Amerini, F. Baseline-free estimation of residual fatigue life using a third order acoustic nonlinear parameter. J. Acoust. Soc. Am. 2011, 130, 1829-1837. [CrossRef]

36. Zhao, Y.; Li, F.; Cao, P. Generation mechanism of nonlinear ultrasonic Lamb waves in thin plates with randomly distributed micro-cracks. Ultrasonics 2017, 79, 60-67. [CrossRef] 
37. Hong, M.; Mao, Z.; Todd, M.D. Uncertainty quantification for acoustic nonlinearity parameter in Lamb wave-based prediction of barely visible impact damage in composites. Mech. Syst. Signal. Process. 2017, 82, 448-460. [CrossRef]

38. Yin, Z.H.; Li, C.; Tie, Y.; Duan, Y.C. Impact Damage Detection in Patch-Repaired CFRP Laminates Using Nonlinear Lamb Waves. Sensors 2021, 21, 219. [CrossRef] [PubMed]

39. Deming, S.N. Quality by designs part 5. Chemtech 1990, 20, 118-120.

40. Alaswad, A.; Benyounis, K.Y.; Olabi, A.G. Employment of finite element analysis and Response Surface Methodology to investigate the geometrical factors in T-type bi-layered tube hydroforming. Adv. Eng. Softw. 2011, 42, 917-926. [CrossRef]

41. Montgomery, D.C. Design and Analysis of Experiments; Springer Texts in Statistics; Springer: Berlin/Heidelberg, Germany, 2017; Volume 101, pp. 853-854. 